Portland State University

PDXScholar

Engineering and Technology Management

Faculty Publications and Presentations

$12-1-2017$

\title{
Improving the Effectiveness of Fuzzy Front End Management: Expanding Stage-Gate Methodologies Through Agile
}

\author{
Aruna Bhatia \\ Portland State University \\ Juchun Cheng \\ Portland State University \\ Sadaf Salek \\ Portland State University \\ Vidhi Chokshi \\ Portland State University \\ Antonie J. Jetter \\ Portland State University, ajetter@pdx.edu
}

Follow this and additional works at: https://pdxscholar.library.pdx.edu/etm_fac

Part of the Engineering Commons

Let us know how access to this document benefits you.

\section{Citation Details}

A. Bhatia, J. Cheng, S. Salek, V. Chokshi and A. Jetter, "Improving the Effectiveness of Fuzzy Front End Management: Expanding Stage-Gate Methodologies through Agile," 2017 Portland International Conference on Management of Engineering and Technology (PICMET), Portland, OR, 2017, pp. 1-8.

This Article is brought to you for free and open access. It has been accepted for inclusion in Engineering and Technology Management Faculty Publications and Presentations by an authorized administrator of PDXScholar. Please contact us if we can make this document more accessible: pdxscholar@pdx.edu. 


\title{
Improving the Effectiveness of Fuzzy Front End Management: Expanding Stage-Gate Methodologies Through Agile
}

\author{
Aruna Bhatia, Juchun Cheng, Sadaf Salek, Vidhi Chokshi, Antonie Jetter \\ Department of Engineering and Technology Management, Portland State University, Portland, Oregon, USA
}

\begin{abstract}
More now than ever before, product development has become more challenging and complex with all the globalization around business today. Understanding the requirements of unfamiliar markets can be very challenging for organizations trying to speed-up their innovations. Also with the advent of globalization there is pressure on everyone to perform better and roll out new products in the market. The fuzzy front end process is very dynamic and unstructured process. By taking advantage of the key characteristics of Agile and Stage-Gate model, an Integrated Agile- Stage- Gate Hybrid model was developed which could help in improving the effectiveness of the fuzzy front end process. The goal of this research is to improve the effectiveness of Fuzzy Front End innovation process by expanding Stage-Gate methodologies through Agile. In order to do this, literature review was done to understand and review various Stage-Gate approaches, focusing on the problems of the Stage-Gate model and solutions provided by the succeeding frameworks. The key contribution of the research is an assessment of different Stage- Gate models which has been developed over the years focusing on their problems and the solutions given by Agile to resolve these problems. Recommendations are made in the end accordingly.
\end{abstract}

Key Concepts:

Fuzzy Front End: A period between when an opportunity for a new product is first considered, and when the product idea is judged ready to enter formal development.

Stage-Gate: A model that helps the firm to move its new product from idea to launch.

Agile Project Management (APM): A conceptual framework which uses a group of development methods based on iterative and incremental development to promote adaptive planning, evolutionary development and delivery.

\section{INTRODUCTION}

With the advent of globalization there is pressure on everyone to perform better and roll out new products in the market with shorter idea-to-launch time. More now than the other times product development has become challenging and complex with all the globalization around business today [1]. Because the customer today is not only exposed to the products or technologies that are manufactured or invented at home, it has access to everything anyone is manufacturing around the globe. Thus, new product development has emerged as a core business activity of any company which is in line with its business strategy. This process however must be managed by using analysis and efficient decision making [2]. Every business is basically at product war of manufacturing and rolling out innovative products in the market in less time. It's the firm's ability to get better at innovating and the process of innovation to get the new products into market faster and with less mistakes that set it apart from the crowd [3].

Companies have been using Stage-Gate project management system to achieve great results in terms of product innovation since a long time till now. Stage-Gate system basically applies the process management methodologies to product innovation process which in turn leads to shorter launch times, fewer mistakes, less wastage and more success [3]. This has been working as expected for a long time but as the market has gone more fluid than ever with expectation changing every now and then; can we still manage to work with the traditional Stage-Gate systems? Or do we need something more adaptive, flexible and scalable [4], which can be changed according to the market needs at that particular time and thus, always lead to a right product. We are in a desired need of a compressed and accelerated product development process. Product development at manufacturing companies is increasingly complex. Linear product development processes, including the traditional Stage-Gate process, cannot support the iterative cycles and external collaboration that characterize today's product development efforts. Hybrid processes combining elements of Agile and Stage-Gate models offer a more flexible alternative to conventional systems [5].

The goal of this research is to improve the effectiveness of Fuzzy Front End innovation process by expanding Stage-Gate methodologies through Agile. We are reviewing different Stage-Gate models used over the time and trying to assess the extent of improvements made so far, as to increase the effectiveness of the product development process focusing on Agile Project Management.

\section{Stage-GAte ApProAches}

This study is basically secondary in nature. The methodology adopted for this study comprises of literature review. A lot of past literature available on Front end management; Agile Project Management, Stage-Gate system, Agile-stage-gate hybrid, etc have been thoroughly analyzed. In the following sections we will discuss various Stage- Gate approaches. 


\section{A. Traditional Stage-Gate System}

Stage-Gate system is a model that helps the firm to move its new product from idea to launch. It serves as a roadmap which helps in managing the new product development process by improving its efficiency and effectiveness. Stage-Gate system results in shorter times to launch, lesser mistakes, less wastage hence, more success [3]. The basic Stage-Gate system is shown in Figure 1.

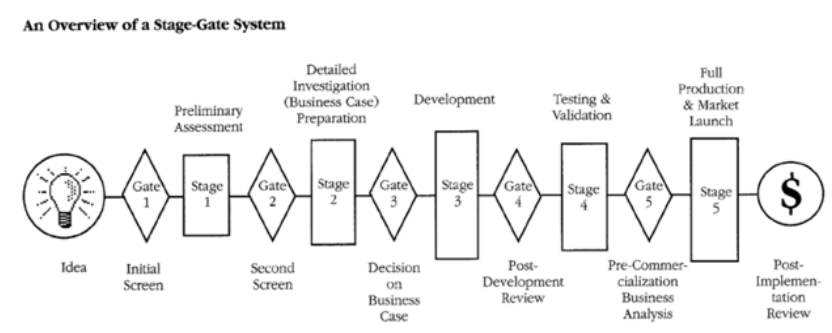

Fig. 1. Traditional Stage-Gate Model (Cooper, 1990)

Here, the focus is on improving the process itself. Process is divided into number of stages and each stage is further divided into number of activities that takes place in that particular stage. There is a set of deliverables expected from each stage. Between each stage there is a checkpoint which is a quality control checkpoint known as gate. Each gate has a set of quality criteria that has to be fulfilled in order to get a go decision at the gate. Each gate also has a set output which is the plan of action for the next stage [3]. Gates have group of senior managers as gatekeepers, who have the expertise to understand the project as well as has the authority to make commitments in terms of resources. They have a pivotal role to play in this system. The project leaders are the drivers of the project from stage to stage. They are the one's responsible to organize the team in order to meet all the requirements of the upcoming gate. Stage-Gate system leads the company from idea to launch and impacts the speed of production, likelihood of the success of the product, ensures discipline in the process, reduces effort wastage, leads to efficient utilization of resources, which eventually increases effectiveness of the overall process of product development [6].

\section{B. New Stage-Gate Approach}

The traditional Stage-Gate was developed with a one- sizefits- all strategy in mind, it was mainly designed for complex development projects [7][8][9]. The four stage model was used as a generic model to guide companies to come up with their own versions of stage gate models. In a study six companies and their stage gate approaches were compared. The stage gate models varied from having four phases or stages to 10 phases or stages. It was further inferred that companies which uses cross functional teams for the development of new products mainly uses the generic four phase stage gate model whereas the companies those which operate mainly in functional matrix use more phases or stages. The generic model serves as a basic architecture that can be referred to or followed to drive the company from idea to launch [10]. Some projects are too small for a full five stage five gate model and some are too big and would need more stages and gates. Each project has its own risk, its own specific resource requirements, which lead to use of different versions of this model to fit business needs and speed up the project [11].

However, after proliferation of different versions of StageGate by companies, Cooper understood the need of a scalable Stage-Gate system and thus he came up with truncated versions of the traditional model which were meant to manage the simpler and lower risk projects [7][8][9]. The model is shown below in Fig 2.

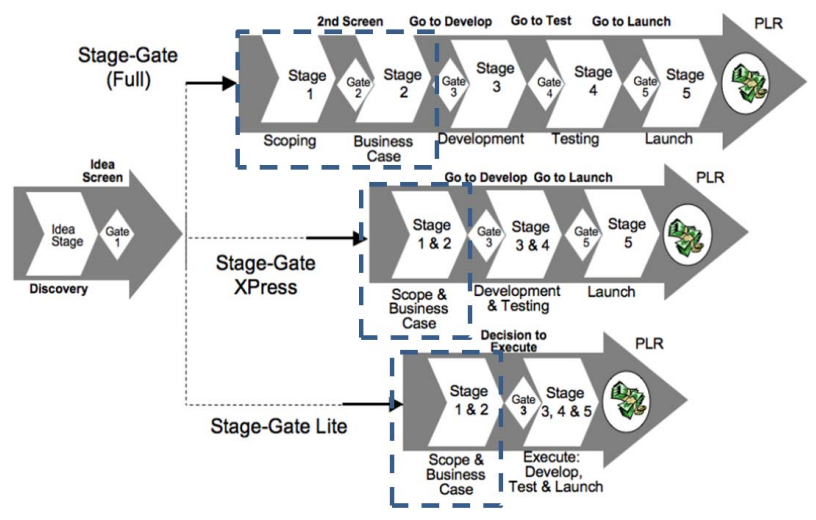

Fig. 2. XPress and Lite Variations of Stage-Gate (Cooper, 2008)

\section{Stage-Gate Limitations/Problems}

Stage-Gate process aims to set an idea to the launch. The main purpose of gates and stages is to help eliminate risks and uncertainties. However standard Stage-Gate carries many problems which make this process not successful leading to loss in cost, time, and reputation. Some of the problems are as follows:

\section{1) Inflexibility}

Some of the issues with Stage-Gates are due to its inherent nature of predicting the process to reduce uncertainty and thus, have less iteration. In today's world market is changing fast. So because of the inflexibility in the nature of Stage-Gate system we cannot adapt as quickly as possible and hence face the losses in the market. Both market as well technology is turbulent these days. We need to act swiftly in gathering new data inputs from the customers, their requirements, the new technology, competitors, etc and thus, adapt as fast as we can. This will lead to a right product in the market [12]. In StageGate system the requirements or criteria for each gate are already fixed for a firm so the projects with asymmetrical uncertainty, which need more time and investment during initial stages will also be weeded of by the Stage-Gate system very early because they will not meet the requirement of time and budget according to the Stage-Gate system [12]. If we would have been a little flexible this idea could have been a novel product in the market. The new Stage-Gate models were able to address this problem partially as the XPress and Lite variations at least introduced some flexibility in terms of scalability of the model [7][8][9].

\section{2) Sequential Processing}

Traditional Stage-Gate is known to be rigid and linear where each activity takes place after the previous activity is 
completed which made the product development process long and time taking [7][9]. The New Stage-Gate model allowed 'simultaneous execution', meaning that activities which in the traditional model were done in series can now overlap and done in parallel within a stage [7][8][9].

\section{3) Weaker Gates and Undefined Gate Keepers}

One of the biggest challenges the Stage-Gate users face deals with making the gates work. Many companies which use the standard Stage-Gate process lack the quality control checkpoints where the gates are not effective. Ineffective gates cause poor projects to proceed further in the stages. Another issue with the gates deals with the lack teeth which act as a blocking mechanism [9]. Due to no teeth or stopping process well integrated, poor projects are seldom killed at the gates. This also leads to the projects moving forward in the stages. The main purpose of gates in the standard process is to eliminate the risk and uncertainties. However, standard process in many companies lack in blocking the projects at the gates. Therefore, in context to the fuzziness in the process, this feature causes loss of budget and higher increase in risk [9].

As the gates are managed by the gatekeepers, the weaker gates also become weaker with inadequate assignment of the gate-keeper. Many companies have difficulties in assigning the right gatekeepers [9]. Many gatekeepers are just assigned based on the seniority status. The gatekeeper is one of the major backbones in the process of fuzziness because they can determine the project's progress and their decision accounts for many correlated variables such as company's time, cost, image, resources, etc. The perfect candidate for the gatekeeper is the person belonging to or has an experience in cross-functional senior group which deals with all the fields such as: Marketing, Sales, Technical, Operational, and Finance rather than just one functional group. The wrong candidate as a gatekeeper with the lack of experience and knowledge affects all the variables in the process by allowing un-necessary projects and removing important projects [7][9]. This problem remained as it is in the New Stage-Gate models too.

\section{4) Lack of Data Integrity}

Data integrity is one of the important factors which helps determine the project's status in the project portfolio in this process of fuzzy front. However, one of the biggest issues faced in the Stage-Gate model is the lack of data integrity. Due to poorly defined process, the project teams are left alone and relied on themselves in terms of type of data to collect the way to obtain data. This causes teams to gather data on their own understanding, which leads to gathering of inconsistent data on the project through different method. Due to inconsistent data, it becomes difficult to rank the effectiveness of the projects on their portfolio management. Apart from affecting the portfolio management, the lack of data integrity process implementation, also causes team to over delivers for the project. This causes higher duration in time, budget, as well as analysis. Therefore, one of the biggest challenges the Stage-Gate process needs to work on is clearly defining the expectations at the gates from the team [9]. New Stage-Gate did not improve on this problem.

5) Demanding much non-value added work in the stages

Another issue with the stage gate process is demanding unnecessary information, template of paperwork at each gate.
Although the templates are useful guides, requesting information not necessary for the project leads to deliverable overkill. This also causes the processes over the time period to become very bulky and many more work gets inserted in the system. Therefore, one of issue the Stage-Gate process needs to improve to make the fuzzy front end more effective is on communicating the requirement of essential information for making decisions at the gate [9]. New Stage-Gate improvised on this problem by dropping or modifying the documents which are not applying to the project [13]

\section{6) Resource Allocation issue}

Allocating proper resources for the project is yet another issue which has been faced in the Stage-Gate model. In some of the meetings dealing with gate reviews, the decision to proceed are made to next stage, however the resources are not committed or properly allocated [7]. The Stage-Gate process deals with committing resources at early stages itself. The issue with this process causes allocation of resources to profitable projects which are beginning in the queue causing scarce for needed allocation for the new projects [9]. New Stage-Gate model had the same limitation.

\section{7) Project Overrun}

In the fuzzy end process, one of the problems regarding project management approach is with the estimation and evaluation of time, budget and task. The delays in time-tomarket would also be caused because of the failure of product definition before entering the development. The issue is the inaccuracy of the estimation of the data which causes project over run. Project overrun causes issues in higher cost, duration and effectiveness of the activities planned [14]. Even New Stage-Gate models did not improvise on this issue.

\section{Agile Project Management (APM)}

\section{A. Introduction of APM}

Project management methodology is a model, which project managers employ for the design, planning, implementation and achievement of their project objectives. Project management methodology is usually defined as a set of methods, techniques, procedure, rules, templates and the best practices to be used on a project [15]. APM is a conceptual framework which uses a group of development methods based on iterative and incremental development to promote adaptive planning, evolutionary development and delivery. Because of the increasing complexity of software development process, APM was firstly introduced to software new-product development process to help product developers rapidly create working software with continuous validation from the customer. Before applying Agile, most companies relied on the Stage-Gate type process which is linear in nature and extensively relies on documents across a fixed set of activities. Compared with traditional Stage-Gate process, APM is lightweight, with faster and nimbler process.

\section{B. APM Process}

APM emphasizes individuals over processes, face-to-face communication over written documents, working software over complete documentation and flexibility over fixed plans. In 
practice, APM breaks the project process into a series of shorttime iteration phases which is usually in 2-4 weeks long with small team. The goal of each phase is to deliver working software release which can be demonstrated to the stakeholders and potentially releasable to the customers. At the beginning of each phase, the planning meetings decide what can be realistically accomplished in the next release sprint within the 2-4 weeks of timeframe. Thus, it is an incremental scope with minimum planning. The feedback from stakeholders and customers might result in change requests in product requirements which need the development team to take action in next release sprint. Thus, APM is very flexible and responsive with "plan on the fly" style adaptability for changes while each iteration process involves full development process [16].

\section{Benefits and Opportunities}

Agile project management provides numerous benefits to project team and products. A cross case study suggested that Agile project management is correlated to increase knowledge sharing and communication, Improve resource coordination, Increase visibility, Achieve the efficiency, Respond to changes and unpredictability and deliver the right product to the customers. Agile implementation helps to have a better product quality by taking a proactive approach to quality to prevent product issues in the first phases. It helps to define and elaborate on requirements just in time so the knowledge of new product development is as relevant as possible [5].

Agile project management helps to satisfy customers by keeping customers involved and engaged throughout the project. It also improves the performance visibility, every member of the project has the right and the opportunity to be updated about the stages of the project and how the project is going at any given time. Agile project management incorporates several practices and methodology for improved predictability, using individual development team speed helps the project team to predict timelines, budgets for releases and performance for individual group meetings [17].

\section{Problems}

However, APM also causes some challenges for the organizations because of the lack of scalability and a lack of management buy-in due to the differences from the Stage-Gate system which most managers are originally comfortable with. It is important that not only to incorporate Agile tools and methods into current process, but also to adapt it into the organizational values [5]. Also, APM uses dedicated resource for each iteration process project for better internal communication. But this might lead to more isolation from other parts of the organization [16].

\section{E. Implementation of APM in Fuzzy Front End (FFE)}

The FFE process has a very dynamic and unstructured process. Understanding the requirements of unfamiliar markets can be very challenging for organizations trying to speed-up their innovations [18]. By taking advantage of the adaptability and flexibility characteristics of APM to deal with uncertainties at the front end process, it could increase the knowledge sharing and communication between members, improve the project resource coordination, and increase the visibility across the project team [5]. The planning can also be more efficient on really important product features based on improved and continuous feedback from customers [16].

\section{InTEGRATION OF APM AND STAGE-GATE SySTEM (HybRID MODELS)}

A One of the arguments that people make is whether we can use agile methodologies with Stage-Gate or if one can be used instead of the other. But in reality, these cannot be a replacement for each other. As Stage-Gate is a macro planning process which drives an idea to a product in market by using a well defined system. Agile which is a micro planning method or a project management method and this can be used in integration with Stage-Gates to increase the overall effectiveness and efficiency of the system [9][19].

Both traditional and agile approaches have their advantage and disadvantages so it is not possible to uniformly assert that one approach is better than another. But, it is often necessary to use both approaches. The need for different approaches to project management could be visible within the organization on a project portfolio level, depending on different project categories in respect to project characteristics, or even on a single project in usage of specifics methods and techniques, depending on requests for specific project phase, and again in regard to project characteristics [20]. With the competition being fierce and the ever changing customer needs and technology innovations, not only the number of stages has to be varied according to the product or company but there is a need of incorporating the new business strategies, approaches, processes and technology to keep on introducing innovative products into the market [10]. Thus, companies started using variations which could make the Stage-Gate system leaner, adaptive, flexible and scalable [11].

The benefits and advantages of Stage-Gate were reviewed and documented in the Cooper article. Such as the discipline, the stages structure, the go/kill decision points and built-in best practices. The benefits of the Scrum version of Agile are less well known to hardware industries, but the experience with Agile-Stage-Gate hybrid suggests that new product development and new front end product can greatly benefit from this approach. This is due to the hybrid model that balances the advantages and challenges of the two different approaches and creates a number of important benefits [4]. The characteristics of both Stage-Gate and Agile project management are summarized in table I below.

One of the approaches of hybrid deals with is integrating agile to Stage-Gate process also known as: Next Generation Idea-to-Launch System. This hybrid is known to be more adaptive, agile oriented, and faster. This approach helps project move at a quicker pace from one milestone to next through frequent experiment and iteration after involving customer's input. The quicker speed is established by overlapping stages and the activities. However, hybrid system does consist of the gates. To make it more effective, it is integrated with the portfolio management and reviews which helps decisions such as Go/Kill and helps prioritize the projects. 
TABLE I. Key Characteristics of Stage-Gate and Agile Project

\begin{tabular}{|c|c|c|}
\hline & Stage-Gate & Agile \\
\hline Type & Macro planning & $\begin{array}{l}\text { Micro planning, } \\
\text { project management }\end{array}$ \\
\hline Scope & Idea to launch & $\begin{array}{l}\text { Development and testing, } \\
\text { can be expanded to pre- } \\
\text { development }\end{array}$ \\
\hline Decision Model & $\begin{array}{l}\text { Investment model- } \\
\text { Go/Kill decisions } \\
\text { involve a senior } \\
\text { governance group }\end{array}$ & $\begin{array}{l}\text { Tactical model--decisions about } \\
\text { actions for next sprint made } \\
\text { largely by self-managed team }\end{array}$ \\
\hline Approach & $\begin{array}{l}\text { Emphasizes on } \\
\text { verification and } \\
\text { validation }\end{array}$ & $\begin{array}{l}\text { Emphasizes on simple design } \\
\text { based on YAGNI (you are } \\
\text { going to need it) }\end{array}$ \\
\hline $\begin{array}{c}\text { Product } \\
\text { Requirements }\end{array}$ & $\begin{array}{l}\text { Stable requirements \& } \\
\text { specs }\end{array}$ & Change often during project \\
\hline Project team size & Large & Small \\
\hline Company culture & $\begin{array}{l}\text { Culture that demands } \\
\text { order }\end{array}$ & Culture that responds to change \\
\hline
\end{tabular}

Also unlike the traditional system which has standard operating procedure where the stage activities are planned and not iterative, the hybrid system process helps overcome those weakness with context based procedure which depends on the uniqueness of the project and also consist of frequent spiral iterations which are more experimental. This makes the process more adaptive and flexible [8].

The Agile-Stage-Gate hybrid approaches provide a framework for dealing with uncertainties and ambiguity in the front-end, accelerates the process through the use of time boxed iterations, and focuses on the results via development of tangible product increments as the measure of progress [4]. It has a built in agile or spiral development, which makes the Stage-Gate more adaptable, so that it can cater to the constantly changing needs of the market. This allows the project team to use several series of the "build- test- feedback- revise" iteration to get to the final product. This helps the developers to continuously incorporate customer feedback and modify the design as per the changing demands even after locking in the product definition thus, introduce the right product in the market. Using spiral developments a company can even take customer feedback in earlier stage than it was supposed to be by presenting the customer with Minimum Viable Product (MVPs) in stage 2 rather than stage 3 [11].

The spirals are built in from the front end stages to the new product development into the testing stage. Voice of customer study is the first spiral in the stage 2 in which team get in contact with the customers to understand their needs, expectation, problems, benefits they expect from the product. Then in the second spiral in the same stage is where the teams comes up with the MVP of proposed product, it should be enough to give the customer the feel for the final product. This helps the team to collect the feedback of the customers and integrate it into the product design. Thus the team finalizes its product definition in Stage 2 specifying what parts of the definition is fixed and what may change with new inputs [9].

An Agile-Stage-Gate hybrid product development model is feasible and will yield to positive results. The company has been using the Hybrid system and process on all major newproduct initiatives for over two years and it has seen that the process has worked well, according to senior management, and has led to down cycle time. Therefore, it will drive much better communication within development teams [4]. The AgileStage-Gate Hybrid model has a major potential for increasing success rates of new product. This model and approach require that the project team interact with users and customers, starting in very early stages. Therefore, the team can get valuable feedback and early market validation [21]. The Hybrid AgileStage-Gate model, using the Scrum version of Agile helps to get the product right, accommodate uncertainty, accelerate development, having focused teams, and improve crossfunctional team which leads to good internal cooperation and communication.

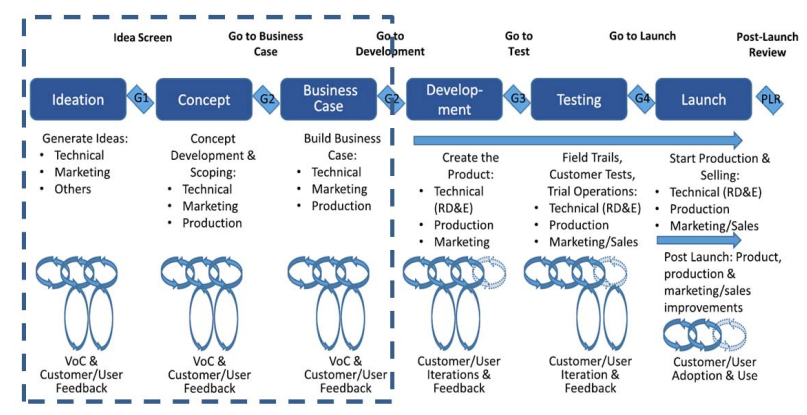

Fig. 3. The Integrated Agile-Stage-Gate Hybrid Model (Cooper \&Sommer 2016)

A model suggested by Cooper recently, clearly shows the integration of APM into Stage-Gate systems. Earlier agile was being used in the technical stages of stage gates like development and testing stages but this framework can be used as basis to use APM in the front end management too [16]. This model suggests using series of "build- test- feedbackrevise" iterations in every stage of the Front end of new product development. All the stages in the Front end like ideation, concept and business case will have sprints called voice of customer study and user feedback. During the spiral Voice of customer study team get in contact with the customers to understand their needs, expectation, problems, benefits they expect from the product at a particular time. Then in the following spiral in the same stage is where the teams come up with a MVP or protocept of proposed product. Team gets the feedback on the protocept and they react accordingly by integrating the relevant changes into the product design. This eventually helps the development team to cope up with the uncertainty and ambiguity making them well equipped to act upon the swift market and technology changes [9][16].

\section{COMPARISON AND REVIEW Of ApProAcheS}

\section{1) Inflexibility}

It is very challenging to speed-up the innovations in unfamiliar markets. The APM approach could provide the flexibility to deal with uncertainty in innovation effort, reducing planning time and improving communication in front end process. In contrast to the traditional approach which emphasizes on planning, flexibility of APM provides the ability to create and respond to changes in order to create value in the 
changing business environment [20]. In APM development, change is accepted and focus is on project execution by deploying the iteration process which is preferably short cycle but comprises all phases [22]. The time scale is fixed and requirements emerge and evolve as the product is developed. It helps to achieve better control of project uncertainties [20]. Also, it can create better visibility in project selections and improve company's [23] front end innovation process [24].

TABLE II. APM Solution to STAGe-GATE Problems

\begin{tabular}{|l|l|l|}
\hline No & Problems with Stage-Gate system & \multicolumn{1}{|c|}{$\begin{array}{c}\text { Solutions provided by Agile project } \\
\text { management }\end{array}$} \\
\hline 1 & Inflexibility & Series of iterations with short cycle time \\
\hline 2 & Sequential Processing & $\begin{array}{l}\text { Incremental approach, activities within as } \\
\text { well as between stages overlapped }\end{array}$ \\
\hline 3 & $\begin{array}{l}\text { Weaker gates and Undefined } \\
\text { Gatekeepers }\end{array}$ & $\begin{array}{l}\text { Increased customer involvement, Improved } \\
\text { internal communication }\end{array}$ \\
\hline 4 & Lack of Data Integrity & $\begin{array}{l}\text { Frequent assessment of data (Product specs, } \\
\text { etc.) through series of iterations to improve } \\
\text { project visibility and prioritizing accordingly }\end{array}$ \\
\hline 5 & Demand of Non- value Added Work & $\begin{array}{l}\text { Simplicity of APM, Fewer rules and less } \\
\text { required documents }\end{array}$ \\
\hline 6 & Resource Allocation Issue & $\begin{array}{l}\text { Commitment of dedicated team resources for } \\
\text { smaller scope and shorter cycle time. }\end{array}$ \\
\hline 7 & Project Overruns & $\begin{array}{l}\text { APM accelerates the speed of the overall } \\
\text { process by smaller scope, short cycle time and } \\
\text { more frequent adjustments. }\end{array}$ \\
\hline
\end{tabular}

\section{2) Sequential Processing}

Agile came in at about time, as a solution to sequential processing. Instead of a sequential development process, the agile methodology follows an incremental approach by delivery MVP (Minimal Viable Product) for each sprint cycle which comprises full development phases and feedback loop. This allows faster response in front end process to deal with the uncertainties. Because of the benefit of APM flexibility, you are allowed to make spec changes or add features more easily to keep up to date with the latest new product development [23]. One of the goals is to have a system to accelerate the projects. Industries are employing a range of methods to accelerate development projects, including overlapping stages and concurrent activities. An important way to accelerate projects is simultaneous execution. Key activities and even entire stages overlap allowing projects to move ahead when information is reliable and stable rather waiting for perfect information. In some cases, it is even acceptable to move activities from one stage to an earlier one and in effect to overlap stages; starting one stage before the previous stages is finished [8].

\section{3) Weaker Gates and Undefined Gatekeepers}

To improve the weaker gates and increase the quality control check point, the iterative review cycle in the early stages with the in-depth customer involvement enhance the gate review process. The early stages typically are made up of several sprints before entering the gates, which will evaluate each increment done in the individual sprint with more micro management view. Also, with smaller team size, the internal communication is more transparent. Hence, each gate is more in-depth that will evaluate all the increments completed in the project as well as a Go/Kill or investment decision point. Many development processes have trouble defining who the gatekeepers are. The quality of the project must be maintained from the beginning of an effort. Hence, the use of Agile project management approach leads the gatekeeper role to be transformed to someone who facilitates the motion of the entire development [4].

\section{4) Lack of Data Integrity}

To improve new product profitability, an effective portfolio management in new product process is helpful to eliminate poor projects and select high-value projects earlier in process so that resource can be allocated more efficiently. In a American Productivity and Quality Center portfolio management study in 2007, the lack of data integrity is one of the top issues identified [9]. Thus, it is essential in Stage-Gate process to define what information is required and better data is received. However, more data does not necessarily mean better business decisions. If the data is wrong, so is the information you are collected, no matter how much data you receive and how fast you can process it. To ensure the data integrity, the input data firstly needs to be sound. In the Preliminary Assessment Stage, the preliminary market, technical and business assessment data is acquired. In Building Business Case stage, it involves much more detailed market research along with technical and manufacturing assessments. In APM practice, the project and deliverable plan is reviewed and updated in shorter cycle time. This means the required assessment data would be adjusted more frequently to better align with the actual product target specifications. The feedback loops would then help the further process of evaluating more opportunities and better assessment process.

\section{5) Demand of Non-value Added Work}

It is essential in APM approach to maintain the simplicity which means few rules and a clear definition of roles, practices, tools and techniques. Rather than trying to impose rigid formal controls in traditional linear methods, APM focuses the needed for customization in the business environment during the front end process. According to the Manifesto for Agile Software Development, simplicity is defined as "the art of maximizing the amount of work not done" [15]. In APM practice, the scope of MVP is just enough to get feedback from customer. Requirement and spec documents are not necessary to understand the requirement and design the product. Documents are only written to serve a need. From the work backlog, the created-value is used to prioritize the works. Participants could set the priority with the customer, and concentrate the efforts to create value with the customers. Evaluation of the accepted product idea and opportunity for innovation is done inside each APM iteration process [24].

\section{6) Resource allocation issue}

Both traditional Stage-Gate and APM have their advantages and disadvantages in resource planning. It is noted that bigger and more complexity projects are more appropriate for traditional Stage-Gate management approach [20]. Traditional Stage-Gate process would require the early commitment for features and schedule. This means resource plan would be decided at the early phase and cause the problems among projects to compete for scarce resources. This would result in the vicious cycle effect to increase the resource buffer in the 
resource planning in case of future change in project scope. However, the front end phases of the project process are usually characterized by high level of uncertainty, unclear project goals or incomplete and unpredictable requests. Thus, the APM approach would be better to resolve the problem of frequent modifications and updates of the project plan. In APM process, each sprint cycle time is shorter with smaller team size to deliver each MVP. Usually, weekly meeting is arranged to review the work of the following week and only the required resource for that week needed for the planning at this phase. Also, if any changes in the front end process happened, it would have less impact on the overall resource allocation and better resource utilization.

\section{7) Project Overruns}

One of the main functions of project management is to forecast and track the progress to avoid overruns in both schedule and cost. Effective project management approach identifies such possible sources of overruns early and mitigate their impact. A common reason for overruns is the inaccuracy of estimation due to the change of conditions which includes requirements or business environments under the high uncertainty in front end process. This would result in design errors which practically mean wrong application of techniques in achieving result and would lead to delay and cost overrun. With fixed product definitions, the traditional Stage-Gate process fails to respond easily and quickly. On the contrary, APM is more adaptive by building early product versions or prototypes via the sprints. The product spec is not locked-in early in the project and evolves over time as the project progresses. The project schedule plan must necessarily be very tentative and high level. From this schedule, the tentative budget and estimated development cost could be determined. If product requirements change, the needed modification to the product's design would be adjusted in earlier stage. Thus, the reassessment to the project schedule and cost could be reflected with lower cost of change. During the front end project phase, it is certainly variable. But as the uncertainty would decreases overtime, the schedule and the budget both become increasingly fixed or stable before the end of the development stage [16].

\section{8) Assessment of the Approaches}

As the earlier sections have discussed on those problems of traditional Stage-Gate and the new Stage-Gate methodologies, we also reviewed how the integrated Stage-Gate-Agile hybrid model addressed and helped on these problems. Table 3 shows our assessment of these approaches focusing on the extent to which these problems were resolved.

After the in-depth review and assessment of all the approaches we can say that even the Integrated- Agile-StageGate hybrid model does not address all the problems that were there in the Stage-Gate model before integration of APM. There are clearly few challenges that still exist. APM itself has its own limitations and problems that it brings to the table with the opportunities that it provides. Sometimes, it is very difficult to find dedicated team to focus on the projects which delays the product development process [16]. Sometimes it becomes difficult to link these isolated dedicated full- time teams to the overall project goals and the organization. Moreover, as APM is a newer concept sometimes there is resistance from not only the managers but from the overall organization to adopt agile into the Stage-Gate system because of the fear that adopting agile means abandoning Stage-Gate. Organizations do not want to accept Agile-Stage-Gate integration because they are so used to Stage-Gate and unfamiliar to APM [16]. Additionally, Agile did not focus much on the Gate part of the Stage-Gate. The major improvements made by APM are within the stages making the process more flexible, adaptive and accelerated. It also helped making the system less bureaucratic, thus making it leaner. But not much special emphasis was given on the gates.

\begin{tabular}{|l|c|c|c|}
\hline Problem & Traditional SG & New SG & Integrated model \\
\hline Inflexibility & & & \\
\hline Sequential processing & 0 & & \\
\hline $\begin{array}{l}\text { Weaker gates and } \\
\text { undefined gate } \\
\text { keepers }\end{array}$ & 0 & & \\
\hline Lack of data integrity & 0 & & \\
\hline $\begin{array}{l}\text { Demand of non-value } \\
\text { added work }\end{array}$ & 0 & & \\
\hline $\begin{array}{l}\text { Resource allocation } \\
\text { issue }\end{array}$ & 0 & & \\
\hline Project overruns & & & \\
\hline \\
$\begin{array}{l}\text { : Problem exists } \\
\text { : Problem addressed to some extent }\end{array}$ \\
$\begin{array}{l}\text { : Problem partially resolved } \\
\text { : Problem resolved substantially }\end{array}$
\end{tabular}

Fig. 4. Summary of Analysis and Review of Approaches

\section{RECOMMENDATION, LIMITATIONS \& FUTURE RESEARCH}

Due to the significant differences in Stage-Gate and Agile approaches, organization should be prepared to embrace changes imposed by the agile approach. For managers, implementation of Agile does not necessarily mean abandon Stage-Gate. Agile can be added to Stage-Gate to create a hybrid to incorporate features and benefits of both. Part of the limitation of this project was that this projects and the main analysis were based on only literature review but in future an empirical study will be beneficial as it will involve actual experiences and collecting primary data which can be used to further analyze and understand the impact of this integration on the effectiveness of Front End Management.

\section{CONCLUSION}

This research reviews the APM practices and Stage-Gate models to understand the integration of these two methods to address the problems of traditional Stage-Gate models. As discussed earlier, Stage-Gate is a macro planning process which guides the product development from idea to launch but due to the uncertainty around market needs and technology trends we need something more agile and flexible in the system to help it cope up. If a team starts the development of a product based on the product definition which was correct at one time and not now, the chances of product success are fickle. Product 
definition is a part of front end and it is only because of integration of APM into Stage-Gates systems that we can have the flexibility to change the product definition when required, so that it can be in line with the external trends. APM when integrated in Stage-Gate allows us to use spiral developments, where the first versions of product (precepts) are created, these are then tested with the customers and seek feedback. The feedback is then integrated into the protocept and next version of the product is created. These iterations help in making the system less bulky by removing unnecessary work and thus, get to the final product faster accelerating the whole new product development process. Integration of Agile into Front end will help to increase the effectiveness as well as efficiency of the front end and eventually the overall process. Using AgileStage-Gate hybrid in the front end as well as in the rest of the product development process will also help to achieve maximum benefit.

Stage-Gate model over the years and has helped many firms to drive their ideas to market. It has evolved from a rigid, linear, controlling and bureaucratic system to a adaptive, flexible, agile and accelerated system. Having said that, we would like to point out that challenges and problems still exist and Agile does not resolve all the problems. There is still scope for improvement by effective execution and optimally utilizing the existing methodologies for improving the front end management of product development process.

\section{REFERENCES}

[1] C. M. Crawford and C. A. Benedetto, "New Products Management," 11th Editi. , McGraw Hill Education, 2014.

[2] A. Khurana and S. R. Rosenthal, "Integrating the Fuzzy Front End of New Product Development.," Sloan Manage. Rev., vol. 38, no. 2, pp. 103-120, 1997.

[3] R. G. Cooper, "Stage-Gate Systems: A New Tool for Managing New Products," Bus. Horiz., vol. 33, no. 3, pp. 44-54, 1990.

[4] R. G. Cooper, "Agile - Stage-Gate Hybrids: The Next Stage for Product Development," Res. Manag., vol. 6308, no. January, pp. 21-28, 2016.

[5] A. F. Sommer, C. Hedegaard, I. Dukovska-Popovska, and K. StegerJensen, "Improved Product Development Performance through Agile/Stage-Gate Hybrids," Res. Technol. Manag., vol. 58, no. 1, pp. $34-44,2015$.

[6] R. G. Cooper, "Stage-Gate ${ }^{\circledR}$ - Your Roadmap for New Product Development," 2016. [Online]. Available: http://www.proddev.com/stage-gate.php.
[7] R. G. Cooper, "What Leading Companies are Doing to Re-invent their NPD Processes," PDMA Visions Mag., no. September, pp. 6-10, 2008.

[8] R. G. Cooper, "Invited Article: What's Next?: After Stage-Gate," Res. Manag., vol. 57, no. 1, pp. 20-31, 2014.

[9] R. Cooper, "Perspective: The Stage-Gate idea to launch process Update, what 's new and nexgen systems," J. Prod. Innov. Manag., vol. 25 , no. 3, pp. 213-232, 2008.

[10] R. Phillips, K. Neailey, and T. Broughton, "A comparative study of six stage-gate approaches to product development," Integr. Manuf. Syst., vol. 10, no. 5, pp. 289-297, 1999.

[11] R. G. Cooper, "How companies are reinventing their idea-to-launch methodologies," Res. Technol. Manag., vol. 52, no. 2, pp. 47-57, 2009.

[12] R. Sethi and Z. Iqbal, "Failure, and Adverse Effect on Novel," J. Mark., vol. 72, no. January, pp. 118-134, 2008.

[13] A. Jetter, F. Albar, and R. C. Sperry, "Unpublished Manuscript: The practice of project management in product development : insights from the high-tech."

[14] R. G. Cooper and S. J. Edgett, "Stage-Gate ${ }^{\circledR}$ and the Critical Success Factors for New Product Development," Prod. Dev. Inst., pp. 1-6, 2006.

[15] E. C. Conforto and D. C. Amaral, "Agile project management and stagegate model-A hybrid framework for technology-based companies," J. Eng. Technol. Manag. - JET-M, vol. 40, pp. 1-14, 2015.

[16] R. G. Cooper and A. F. Sommer, "Agile-Stage-Gate: New idea-tolaunch method for manufactured new products is faster, more responsive," Ind. Mark. Manag., 2016.

[17] Association of Project Managers, "The Practical Adoption of Agile Methodologies," no. May, pp. 1-36, 2015.

[18] J. Utterback, M. Meyer, T. Tuff, and L. Richardson, "When Speeding Concepts To Market Can Be a Mistake," Interfaces (Providence)., vol. 22, no. 4, pp. 24-37, 1992.

[19] R. G. Cooper, "White Paper: Stage-Gate and Agile Development: Debunking the Myths Summary: Many IT developers use the Agile method - a series of rapidly-executed sprints and scrums - as," 2015.

[20] M. Špundak, "Mixed Agile/Traditional Project Management Methodology - Reality or Illusion?," Procedia - Soc. Behav. Sci., vol. 119, pp. 939-948, 2014.

[21] T. Vedsmand, "Integrating Agile with Stage-Gate ${ }^{\circledR}$ - How New AgileScrum Methods Lead to Faster and Better Innovation Integrating Agile with Stage-Gate $\mathbb{R}$ - How New Agile-Scrum Methods Lead to Faster and Better Innovation," no. August, pp. 1-15, 2016.

[22] S. Augustine, "Agile Project Management," Pace Pacing Clin. Electrophysiol., vol. 48, no. 12, pp. 1-16, 2008.

[23] I. Oracle, "Oracle ${ }^{\circledR}$ Agile Product Lifecycle Management for," no. June, 2013.

[24] F. Blindenbach-Driessen, J. Van Den Ende, and W. Gonzalez, "Applying Agile Project Management to Predevelopment Stages of Innovation,” Int. J. Innov. Technol. Manag., vol. 11, no. 4, p. 1450020, 2014 